\title{
Developing a Valid and Reliable Instrument to Predict the Protective Sexual Behaviors in Women at Risk of Human Immunodeficiency Virus
}

\author{
Razieh Lotfi ${ }^{1,2} ;$ Fahimeh Ramezani Tehrani $^{3,}$; Farideh Yaghmaei ${ }^{4}$; Ebrahim Hajizadeh $^{5}$ \\ ${ }^{1}$ Social Determinants of Health Research Center, Alborz University of Medical Sciences, Karaj, IR Iran \\ 2 Department of Midwifery and Reproductive Health, Alborz University of Medical Sciences, Karaj, IR Iran \\ 3 Reproductive Endocrinology Research Center, Research Institute for Endocrine Sciences, Shahid Beheshti University of Medical Sciences, Tehran, IR Iran \\ ${ }_{4}^{4}$ Deproductive Endocrinology Research Center, Research Institute for Endocrine Sciences, \\ ${ }_{5}^{4}$ Department of Health, Shahid Beheshti University of Medical Sciences,
${ }_{\text {Department of Biostatistics, Tarbiat Modares University, Tehran, IR Iran }}$ \\ ${ }^{*}$ Corresponding Author: Fahimeh Ramezani Tehrani, Research Center of Reproductive Endocrinology, Research Institute for Endocrine Sciences, Shahid Beheshti University of Medi- \\ cal Sciences, Tehran, IR Iran. Tel: +98-2122432500, Fax:+98-2122416264, E-mail: ramezani@endocrine.ac.ir
}

Received: September 6, 2013; Revised:April 12, 2014; Accepted: July 16, 2014

\begin{abstract}
Background: One much needed tool to assist with the monitoring and evaluation of Human Immunodeficiency Virus (HIV) prevention programs is to provide a valid instrument to measure protective sexual behavior and related factors.

Objectives: The current study aimed to design a valid and reliable instrument to predict the protective sexual behaviors of women at risk of HIV in Iran.

Patients and Methods: The current study was a sequential mixed cross-sectional and methodological research. Initially, via a qualitative research, constructs and factors associated with sexual protective behavior of women at risk were identified through 25 indepth interviews. The questionnaire on predictors of protective sexual behaviors in women at risk of HIV (PSPB) was designed based on a qualitative study, and then its qualitative validity, content, and construct validity were evaluated. Exploratory factor analysis was performed and 200 women at risk participated.

Results: Seven concepts emerged after exploratory factor analysis of the 48 items. The content validity ratio (CVR) of the questionnaire constructs were 0.55 to 0.76 , and content validity index (CVI) structure was 0.86 to 0.95 . Cronbach's alpha coefficient for the entire questionnaire was 0.78 , and correlation coefficient of the test-retest reliability for the constructs was from 0.73 to 0.89 .

Conclusions:The current study proved the capability of the predictors of sexual protective behavior in women at risk for HIV questionnaire as a valid and reliable instrument for the Iranian community.
\end{abstract}

Keywords:Vulnerable Populations; Women; Questionnaires

\section{Background}

Despite the progress achieved in the past three decades, Human Immunodeficiency Virus/ Human Immunodeficiency Virus Infection (HIV/AIDS) is still considered a serious public health issue (1). This infection, in some subgroups in Iran which are at higher risk for HIV transmission, exists in form of an epidemic and is extensively spreading in most parts of the world. These subgroups include female sex workers, drug users, and spouses who are HIV positive and act as a vehicle to infect the other people in the community (2). It is estimated that around 92'000 people in Iran are infected with HIV/AIDS (1). In Iran, the primary means of HIV/AIDS transmission among women is through heterosexual sex and there are serious concerns regarding the spread of this disease in the country (3).

In addition to biological factors, social factors also play a role in women's HIV risks (4). In the first quarter of 2011, sexual transmission has accounted for $21.1 \%$ of the total individuals infected with HIV/AIDS (5). Access to reliable and accurate information regarding the behaviors of subgroups that are at risk of HIV/AIDS is important to keep track of the epidemic and program planning, and to form the development of future prevention programs (6). Therefore, as the first step to assess the predictors of protective sexual behaviors of women at risk for HIV/ AIDS, it is necessary to identify the constructs, important, and influencing concepts for these behaviors. In the next stage of the research, appropriate tools to assess protective sexual behaviors can be designed.

Currently, most of the questionnaires and their constructs to predict and assess protective sexual behaviors are patterned after the ones in the West and are used in the community and in different groups of the population; whereas, these models are not very successful in predicting preventive interventions for $\operatorname{HIV}(7,8)$. The available scales developed to explore HIV related sexual behavior, considered individual concepts such as knowledge (9), attitude to the condom (10), self-efficacy to condom use (11), and the perceived risks (12) that are not the entire variables influencing HIV related behaviors. Considering the different social and economic contexts of these behaviors in different countries, a valid and ap-

Copyright ( ) 2014, Iranian Red Crescent Medical Journal; Published by Kowsar. This is an open-access article distributed under the terms of the Creative Commons Attribution-NonCommercial 4.0 International License (http://creativecommons.org/licenses/by-nc/4.0/) which permits copy and redistribute the material just in noncommercial usages, provided the original work is properly cited. 
propriate instrument inherent to the social and cultural needs of the country must be provided, especially on the sensitive issues such as sexual behavior.

\section{Objectives}

As there are no gender sensitive scales in Iranian population, the current study was the first and aimed to design a valid and reliable questionnaire within the ecological framework that conforms to the cultural and social conditions of the Iranian population in order to predict protective sexual behaviors of women at risk of HIV.

\section{Patients and Methods}

\subsection{Qualitative Study}

The present cross-sectional and methodological study aimed to develop a valid and reliable instrument and was conducted in Tehran, Iran, in 2012 (13). The first step in the process of developing the questionnaire is a deep understanding of the concepts (14). The first stage of the study involved a qualitative study of protective sexual behaviors. Structures and relevant factors associated with the protective sexual behaviors of women at risk were identified through in-depth interviews based on a semistructured interview guide with 25 women at risk aged 2149 years. Participants were selected from those who came to the Voluntary Counseling and Testing (VCT) centers of the Shahid Behashti University of Medical Sciences and Non-governmental Organization (NGO) Drop-in-Centers (DICs) in Iran. Data collection and analysis was done using the grounded theory approach.

Constructs and variables identified from the qualitative study were as follows: Skills to negotiate condom and control sexual excitement, situational factors, social support, ability to use condom under the influence of drug use, male dominance in sexual decision making, attitudes towards condoms, and prioritization of male sexual needs. In the next step, items for the predictors of protective sexual behaviors of women at risk of HIV/AIDS questionnaire were determined based on the qualitative study and a review of the literature (9-12).

\subsection{Initial Pool and Psychometric Characteristics}

The initial pool of the items was composed of 81 items. Construct on knowledge was designed as dichotomy. In the next phase, in order to verify the validity of the questionnaire, qualitative face validity, and content and construct validity were assessed.

In terms of assessing fluency in writing and appropriate phrasing, the questionnaire was analyzed through a face-to-face method with the participation of 12 individuals, and then modifications were implemented in order to achieve qualitative validity. In order to evaluate the content validity of the questionnaire quantitatively; the content validity ratio (CVR) and content validity index (CVI) were used.
To validate a questionnaire, a CVR value is computed for each item. The CVR is an item statistic that is useful to reject or retain a specific item. The ratio of content validity was calculated by summing up the comments of the 14 experts from different disciplines including; health education, reproductive health, midwifery, nursing, epidemiology and researchers and experts from Center for AIDS Control in the Ministry of Health, and also experts from the National AIDS Research Centre, then the necessary modifications were implemented. For this purpose, these experts were asked to assess each item based on Lawshe scale (15). Data obtained from a panel of fourteen expert judges were analyzed. The following formula was devised for the content validity ratio (CVR):

$$
\mathrm{CVR}=\frac{\mathrm{ne}-N / 2}{N / 2}
$$

In which the ne is the number of panelists indicating essential, and $\mathrm{N}$ is the total number of panelists. Based on the Lawshe's table, when total number of the panelists is 14 , as in the present study, a minimum value of CVR 51 is required to satisfy the five percent level (15). For CVI, the 12 experts used a 4-point Likert scale to assess the questionnaire in order to identify the following criteria: relevance, simplicity and clarity of statements for each item (16). Ceiling effect and floor effect for all of the constructs were under $20 \%$.

Participants of the present study included women who were at risk of HIV, including drug injecting married wives, wives with HIV positive husbands, wives with husbands who were taking narcotics and psychotropic substances, and wives of husbands who had multiple sexual partners. These women were referred to the Voluntary Counseling and Testing (VCT) centers of the Shahid Beheshti University of Medical Sciences (three centers), and four NGO Drop-in-Centers (DICs) in Tehran, aged 18 years and above, were Farsi speakers residing in Tehran and had sexual intercourse experience in the past three months. Women with severe psychological disorders such as severe mental disorders or psychosis based on medical examination (two cases), transgender (o case), HIV positive (1) and women who were not interested to continue to participate in the study and the corresponding data were incomplete (six cases) were excluded.

In the current study, exploratory factor analysis was used to assess construct validity. Based on the qualitative study that revealed seven concepts concerning protective sexual behaviors of women at risk of HIV, and the rule that 30 samples should be selected per construct(17), the sample size was determined 210. In order to analyze the exploratory factors, the Principal Component Analysis was used and factors were extracted by the oblique factors approach. Therefore, 200 women at risk of HIV aged 19 to 49 years participated in the current study. The cut-off point of 0.35 was considered as a minimum load 
factor required to maintain each item (18). In the next phase, the reliability of the questionnaire was assessed by internal consistency (Cronbach's alpha with KuderRichardson 20) and stability (test-retest). Cronbach's alpha coefficient was calculated for each factor, and the questionnaire as a whole, for 30 samples. Also, KuderRichardson 20 was calculated to construct knowledge by 30 samples. According to the existing sources, the coefficient alpha for standard reliability of a tool was set at 0.7 or higher; however, for descriptive studies, the acceptable alpha value was greater than 0.6 (19). In order to determine the reliability of the questionnaire, the test-retest was applied to the 20 participants and was repeated after two weeks. Convenience sampling was used. After obtaining the necessary permits, the research was initiated and after obtaining informed consent from the participants, the data collection was implemented. Data were analyzed by SPSS software version 19. The current study was approved by Ethics Committee of Shahid Beheshti University of Medical Sciences on June 2012.

\section{Results}

Two hundred women at risk of HIV, aged 19-49 years participated in the current study. Participants' demographic information and information regarding drug use are shown in Table 1 . The marriage age in $40 \%$ of the cases was under 16 . None of them had a monthly income more than $\$ 500$, and $38.5 \%$ of these women had six or more sexual partners in their lifetime. Only $29 \%$ of the participants used condoms in their last sexual intercourse and 37.5\% of them expressed that they abstained from using condom due to their partner's disapproval. Only $13 \%$ of the participants had always used male condoms in their sexual relationships for the last three months. Nearly $50 \%$ of the participants had transactional sexual relationships.

\subsection{CVR and CVI}

Assessing the questionnaire for CVR showed that 31 items must be deleted, since they had not met the necessary scores. The average CVR for the constructs of the questionnaire were 0.55 to 0.76 . Also, two items were deleted after calculating their CVI. The mean content validity index of the structures was 0.86 to 0.95 .

\subsection{Construct Validity}

In data reduction phase, principal components analysis (PCA) was used as the extraction method oblique (directoblimin) rotation (18). Decision making on the number of factors to retain for rotation was based on both the Kaiser criteria (eigenvalues more than one) and the Scree plot test (18). Seven factors emerged in this way. Items with a minimum 0.35 coefficient were retained. Constructs were maintained with an Eigen value of more than one. Since the Kaiser-Meyer-Olkin (KMO) value greater than 0.85 was obtained, the quality of factor analysis in KMO was considered adequate. In this sequence, to predict the model, 48 items in the form of seven factors with the variance of $51.9 \%$ were detected. The number of items for each construct had the following sequence: Skills to negotiate condoms and control excitement (16 items), situational factors (four items), social support (six items), ability to use condom despite the influence of drugs (four items), male dominance in sexual decision making (seven items), attitudes towards condom (four items), and sexual needs of male in priority (three items). Four items had been loaded on more than one factor; therefore, due to their complexity (20) were deleted. Results of the Exploratory Factor Analysis are presented in Table 2. Table 3 shows Cronbach's alpha coefficient for the constructs.

Since rating the knowledge on HIV construct had two values, the Kuder-Richardson 20 was used to assess the internal consistency and the extracted value was 0.79 . The Cronbach's alpha coefficient for the whole questionnaire was 0.78. Correlation and Cronbach's alpha coefficient on the questionnaire constructs are shown in Table 3.

\begin{tabular}{|c|c|c|}
\hline Variable & Number & Percentage \\
\hline \multicolumn{3}{|l|}{ Age, $y$} \\
\hline $21-29$ & 50 & 25 \\
\hline $30-39$ & 78 & 39 \\
\hline $40-49$ & 72 & 36 \\
\hline \multicolumn{3}{|l|}{ Education } \\
\hline Illiterate & 21 & 10.5 \\
\hline Primary and Guidance school & 93 & 46.5 \\
\hline High school and Diploma & 64 & 32 \\
\hline Higher education & 22 & 11 \\
\hline \multicolumn{3}{|l|}{ Marital status } \\
\hline Married & 107 & 53.5 \\
\hline Divorced & 71 & 35.5 \\
\hline Widow & 10 & 5 \\
\hline Single & 12 & 6 \\
\hline \multicolumn{3}{|l|}{ Number of children } \\
\hline 0 & 40 & 20 \\
\hline $1-2$ & 104 & 52 \\
\hline 3 and more & 56 & 28 \\
\hline \multicolumn{3}{|l|}{ Homeless } \\
\hline Yes & 50 & 25 \\
\hline No & 150 & 75 \\
\hline \multicolumn{3}{|l|}{ Drug abuse in the last year } \\
\hline Yes & 143 & 71.5 \\
\hline No & 57 & 28.5 \\
\hline
\end{tabular}


Lotfi Ret al.

\begin{tabular}{|c|c|c|c|c|c|c|c|}
\hline \multirow[t]{2}{*}{ Item } & \multicolumn{7}{|c|}{ Components } \\
\hline & $\mathbf{1}$ & 2 & 3 & 4 & 5 & 6 & 7 \\
\hline $\begin{array}{l}\text { When I know that my husband/sexual partner does not agree to use condoms, it is no } \\
\text { use insisting }\end{array}$ & 0.812 & & & & & & \\
\hline I never have sexual relationship without condoms & 0.808 & & & & & & \\
\hline If the spouse/sexual partner abstain from using condoms, I give up & 0.795 & & & & & & \\
\hline $\begin{array}{l}\text { Regarding the use or abstaining from the use of condoms, it is the only husband/sexual } \\
\text { partner who makes the decision }\end{array}$ & 0.726 & & & & & & \\
\hline $\begin{array}{l}\text { If a man requests, the woman should agree to have sexual relationship without con- } \\
\text { doms }\end{array}$ & 0.726 & & & & & & \\
\hline $\begin{array}{l}\text { If my husband/partner does not agree to use condom, I have no choice but to oblige to } \\
\text { sex without condoms }\end{array}$ & 0.718 & & & & & & \\
\hline $\begin{array}{l}\text { If the husband/partner dislikes condom, I don't have the ability to change his attitude } \\
\text { towards condoms }\end{array}$ & 0.711 & & & & & & \\
\hline $\begin{array}{l}\text { When the sexual emotions of my husband/ partner is strong, my appeal to use condoms } \\
\text { will be useless }\end{array}$ & 0.685 & & & & & & \\
\hline When my sexual desire is very strong, I don't care anymore to use condoms & 0.667 & & & & & & \\
\hline $\begin{array}{l}\text { If my husband/partner loves me intensely, I would willingly have sexual relation with- } \\
\text { out condoms }\end{array}$ & 0.657 & & & & & & \\
\hline My husband or most of my sexual partners never agree to use condoms & 0.656 & & & & & & \\
\hline When I cannot avail of condoms, I have sex without it & 0.644 & & & & & & \\
\hline By any means I convince my husband/ sexual partner to use condoms & 0.616 & & & & & & \\
\hline $\begin{array}{l}\text { With regards to use or abstain from using condom, my husband/ sexual partner and I } \\
\text { make the decision together }\end{array}$ & 0.615 & & & & & & \\
\hline I'm always quite sure of myself to be able to use condoms & 0.560 & & & & & & \\
\hline My husband/sexual partner respects my opinion regarding the use of condoms & 0.370 & & & & & & \\
\hline $\begin{array}{l}\text { Have you ever established a sexual relationship in order to obtain drugs, narcotics, or } \\
\text { psychotropic drugs? }\end{array}$ & & 0.847 & & & & & \\
\hline Have you ever entered into a sexual relationship in order to earn money? & & 0.825 & & & & & \\
\hline During the last three months, while under the influence of drugs, did you also have sex? & & 0.804 & & & & & \\
\hline During the last three months, while under the influence of alcohol, did you have sex? & & 0.598 & & & & & \\
\hline I can get free counseling about HIV whenever I want & & & 0.701 & & & & \\
\hline I can be tested for HIV whenever I want & & & 0.696 & & & & \\
\hline Free HIV counseling is accessible & & & 0.691 & & & & \\
\hline I get free condoms from counseling centers & & & 0.668 & & & & \\
\hline I have enough knowledge about the preventive role of condoms in HIV & & & 0.479 & & & & \\
\hline Condom access is convenient & & & 0.383 & & & & \\
\hline I know how to use male condoms on my partner's penis & & & & 0.681 & & & \\
\hline I can use condoms even if I am under the influence of alcohol & & & & 0.671 & & & \\
\hline I can use condoms even if I am under the influence of drugs & & & & 0.630 & & & \\
\hline I usually have condoms with myself & & & & 0.483 & & & \\
\hline It is not desirable for a woman to suggest condoms to her husband & & & & & 0.753 & & \\
\hline This is a man that must offer when the couple must have sex & & & & & 0.634 & & \\
\hline This is a man who should initiate sex & & & & & 0.632 & & \\
\hline This is a man who should offer how the couple should have sex & & & & & 0.626 & & \\
\hline This is a man who should make a decision in sexual relationship & & & & & 0.608 & & \\
\hline It is not necessary for a woman to be submissive all the time & & & & & 0.498 & & \\
\hline A woman should be always dependent on a man & & & & & 0.424 & & \\
\hline Condoms can decrease male sexual desire & & & & & & 0.666 & \\
\hline Condoms can decrease female sexual desire & & & & & & 0.649 & \\
\hline Condoms can prevent HIV & & & & & & 0.539 & \\
\hline Condoms can reduce trust between the couples & & & & & & 0.478 & \\
\hline Sexual needs of male is more than female & & & & & & & 0.624 \\
\hline This is the most important thing that a male enjoys the sexual relationship & & & & & & & 0.486 \\
\hline A wife should not stop the sexual demand of her husband & & & & & & & 0.372 \\
\hline Component number & 1 & 2 & 3 & 4 & 5 & 6 & 7 \\
\hline Cumulative percent & 25.78 & 32.58 & 37.24 & 41.61 & 45.37 & 48.70 & 51.87 \\
\hline
\end{tabular}

a Extraction Method: Principal Component Analysis. Rotation Method: Oblimin with Kaiser Normalization. 
Lotfi Ret al.

Table 3. The Cronbach's Alpha Coefficient for Constructs

\begin{tabular}{lcc}
\hline Construct & Cronbach's Alpha & Correlation Coefficient \\
\hline Skills to negotiate condoms and control excitements & 0.84 & 0.91 \\
\hline Situational factors & 0.80 & 0.84 \\
\hline Social support & 0.71 & 0.88 \\
\hline Ability to use condom despite the influence of drugs & 0.64 & 0.78 \\
Male dominance in sexual decision making & 0.82 & 0.80 \\
\hline Attitudes towards condom & 0.54 & 0.78 \\
\hline Sexual needs of male in priority & 0.54 & 0.73 \\
\hline
\end{tabular}

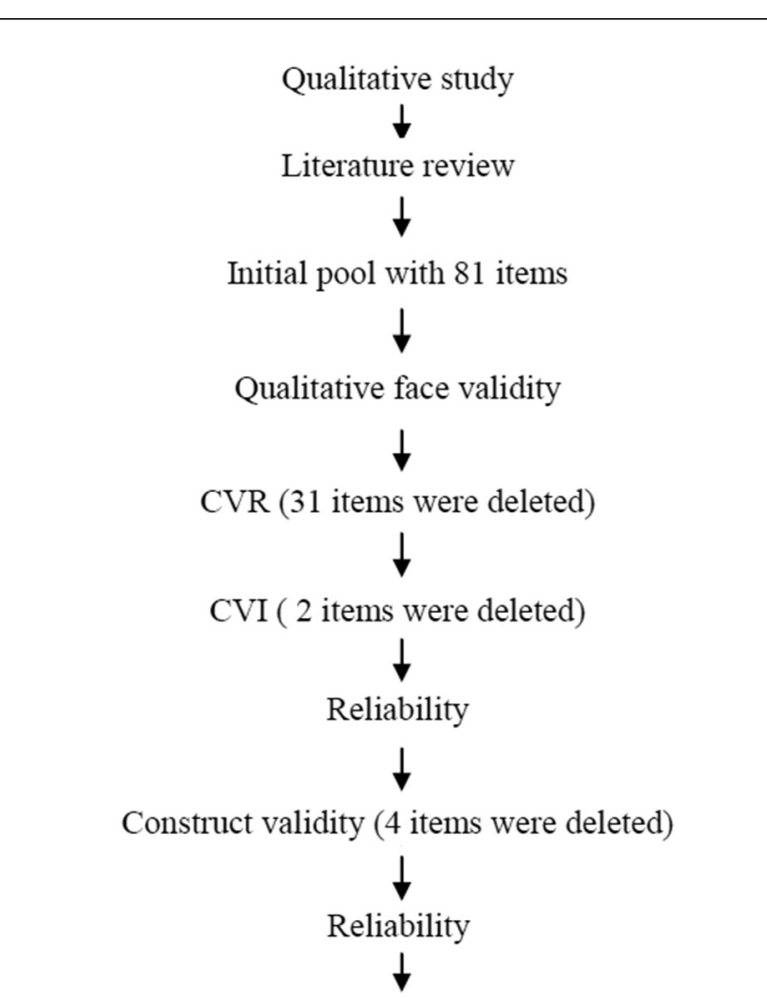

Final questionnaire including 6 construct and 44 items

Figure 1. Steps of the Study Stages

\section{Discussion}

Although various scales are designed worldwide to assess sexual protective behaviors in the communities, to date, there has been no scale to examine these constructs while conforming to the social and cultural conditions of the Iranian population. The appropriateness of the developed questionnaire relies on the fact that it enables the risk to be monitored within a population at risk of HIV by taking into account many important factors influencing HIV prevention.

Since the goal of most HIV programs and preventive interventions is the use of condoms as a protective sexual behavior (4), the present questionnaire would be able to identify the women at risk and also monitor and evaluate HIV preventive programs. Therefore, its application is important both in terms of clinical and in research. The existing models in the context of HIV prevention is mainly focused on cognitive and individual structures, and often the role of environmental and structural factors are overlooked (21), while factors such as stereotypical schema and partner acceptance of condom use had important roles $(21,22)$. Therefore available instruments are designed using an individual framework. The instrument designed in the current study was within the ecological framework and its construct was formulated based on the concepts explored in the qualitative study.

Findings of the current study with mixed methodology showed important constructs related to protective behaviors. It was determined that, although variables such as attitudes toward condoms, and perceived risk regarding HIV, are of great importance in order to adopt this protective sexual behavior, it is not sufficient for women at risk of HIV (23-26). Other concepts such as social support in the area of HIV prevention, and also stereotypical gender roles which are considered as environmental and structural factors are considered to play a significant role for women at risk of HIV.

Validity of the questionnaire was evaluated and confirmed by qualitative face validity, CVR, CVI, and construct validity. In this evaluation, more than 33 items which did not meet the needed requirements were excluded; all these excluded items were taken from the review of articles. This point can indicate the importance and the urgency of developing indigenous tools that conform to the culture of the community in order to evaluate sensitive topics such as issues on sexual behavior.

Using exploratory factor analysis, construct validity showed that the protective sexual behavior of women at risk of HIV in the present study had seven factors. All the existing constructs and variables in the questionnaire regarding the use of condoms as a sexual protective behavior showed a meaningful statistical relationship which was another reason to confirm the construct validity. Although the alpha coefficient of the constructs, attitudes towards condoms, ability to use condoms despite the influence of drugs and the priority of male sexual satisfaction got a weak rating in the evaluation, the limited 
number of items in this construct (three and four items) as the total item correlation was from 0.3 to 0.4 in the constructs; therefore, the reliability of these constructs are within the acceptable range.

The predictive factors of protective sexual behaviors of women at risk for HIV questionnaire designed in the current study was composed of seven constructs and 44 items and required 15 minutes to complete. Despite being the only available questionnaire used for the socially vulnerable women, its complexity, and lengthiness, and being composed of a large volume of questions resulted in decreasing the accuracy of data and loss of concentration the participants, but this questionnaire had its advantages. In addition, the presence of diverse groups of women at risk in the present study was considered as another strong point to this questionnaire.

There were several limitations to the current paper. Since it was difficult to access the risky women in the community, the current study relies on convenience sampling method. Many studies revealed that women tended to under-report their sexual behaviors especially in conservative countries, but the current research did its best to lessen the stress of the participants to build a safe environment to obtain more accurate data on sexual behaviors.

However, considering the importance of the present questionnaire and the fact that the current study was a preliminary study; therefore, more studies are needed in order to improve it. Evidently, further studies with larger sample sizes and also randomized sampling could help with a better presentation of the relationships between the existing constructs in the questionnaire and a step towards improving it.

In general, psychometric properties of each construct including internal consistency and construct validity for the questionnaire were satisfactory and results of the current study revealed that the current questionnaire (PSPB) was a valid and a reliable tool to assess at risk women in the Iranian community.

\section{Acknowledgements}

The authors would like to acknowledge their gratitude to the individuals who willingly participated and shared their time and experience in order to make this study possible. This research was conducted in partial fulfillment of a PhD degree in Reproductive Health at Shahid Beheshti University of Medical Sciences

\section{Authors' Contributions}

Razieh Lotfi contributed to study design, data gathering and analysis, and manuscript drafting. Fahimeh Ramezani Tehrani contributed to study design, analysis, manuscript editing and critical discussion. Farideh Yaghmaei contributed in study design and critical discussion. Ebrahim Hajizadeh contributes in study design and statistical analysis. All authors read and approved the final manuscript.

\section{Funding/Support}

The authors wish to thank Shahid Beheshti University of Medical Sciences for its approval and funding.

\section{References}

1. UNAIDS. [updated 2010]; Islamic Republic of Iran Country Report on Monitoring of the United Nations General Assembly Special Session on HIV and AIDS. Iran Ministry of Health and Medical Education. National AIDS Committee Secretariat. 2010. Available from: www. unaids.org/fr/dataanalysis/file,33662,www.unaids.org/fr/dataanalysis/file.

2. Miller S, Exner TM, Williams SP, Ehrhardt AA. A gender-specific intervention for at-risk women in the USA. AIDS Care. 2000;12(5):603-12.

3. Forouzan AS, Jorjoran Shushtari Z, Sajjadi H, Salimi Y, Dejman M Social Support Network among People Living with HIV/AIDS in Iran. AIDS res treat J. 2013;2013.

4. Gupta GR, Parkhurst JO, Ogden JA, Aggleton P, Mahal A. Structural approaches to HIV prevention. Lancet. 2008;372(9640):764-75.

5. Iran Ministry of Health and Medical Education. Disease Management Center. The latest statistics of HIV/AIDS in Islamic Republic of Iran 2011. 2011. Available from: WWW.iranhiv.com.

6. Walker N, Garcia-Calleja JM, Heaton L, Asamoah-Odei E, Poumerol G, Lazzari S, et al. Epidemiological analysis of the quality of HIV sero-surveillance in the world: how well do we track the epidemic? AIDS. 2001;15(12):1545-54.

7. Boileau C, Vissandjee B, Nguyen VK, Rashed S, Sylla M, Zunzunegui MV. Gender dynamics and sexual norms among youth in Mali in the context of HIV/AIDS prevention. Afr J Reprod Health. 2008;12(3):173-84.

8. Hajiabdolbaghi M, Razani N, Karami N, Kheirandish P, Mohraz M, Rasoolinejad M, et al. Insights from a survey of sexual behavior among a group of at-risk women in Tehran, Iran, 2006. AIDS Educ Prev. 2007;19(6):519-30.

9. Carey MP, Schroder KE. Development and psychometric evaluation of the brief HIV Knowledge Questionnaire. AIDS Educ Prev. 2002;14(2):172-82.

10. Helweg-Larsen M, Collins BE. The UCLA Multidimensional Condom Attitudes Scale: documenting the complex determinants of condom use in college students. Health Psychol.1994;13(3):224-37.

11. Brien TM, Thombs DL, Mahoney CA, Wallnau L. Dimensions of self-efficacy among three distinct groups of condom users. J Am Coll Health. 1994;42(4):167-74.

12. Catania JA, Kegeles SM, Coates TJ. Towards an understanding of risk behavior: an AIDS risk reduction model (ARRM). Health Educ Q.1990;17(1):53-72.

13. LoBiondo-Wood G, Haber J. Nursing research: Methods, critical appraisal, and utilization 6 ed New York: Mosby; 2006.

14. Haynes SN, Richard DCS, Kubany ES. Content validity in psychological assessment: A functional approach to concepts and methods. Psy Assas J. 1995;7(3):238-47.

15. Wynd CA, Schmidt B, Schaefer MA. Two quantitative approaches for estimating content validity. WestJ Nurs Res. 2003;25(5):508-18.

16. Polit DF, Beck CT. Essentials of Nursing Research Methods, Ap praisal and Utilization. 16 ed Philadelphia: Lippincott Williams \& Wilkins; 2006

17. Burns N, Grove SK. The Practice of Nursing Research; Conduct, Critique and Utilization. 5 ed Philadelphia: Elsevier Saunders Co;2005.

18. Velicer WF, Jackson D. Component Analysis versus Common Factor Analysis: Some Further Observations. Multivar Behav Res J. 1990;25(1):97-114.

19. Carmines EG, Zeller RA. Reliability and validity assessment.CA Thousand Oaks, Sage; 1991.

20. Rojanapithayakorn W. The $100 \%$ condom use programme in Asia Reprod Health Matters. 2006;14(28):41-52.

21. Rosenthal L, Levy SR, Earnshaw VA. Social Dominance Orientation Relates to Believing Men Should Dominate Sexually, Sexual Self-Efficacy, and Taking Free Female Condoms Among Undergraduate Women and Men. Sex Roles. 2012;67(11-12):659-69. 


\section{Lotfi Ret al.}

22. Chitalu N, Mumbi M, Cook R, Weiss SM, Jones D. The Impact of Key HIV Intervention Components as Predictors of Sexual Barrier Use: The Zambia Partner Project. J Int Assoc Provid AIDS Care. 2014.

23. Ehrhardt AA, Exner TM, Hoffman S, Silberman I, Yingling S, Adams-Skinner J, et al. AIDS Behav J. 2002;6(1):1-13.

24. Cutrona CE, Russell D. The provisions of social relationships and adaptation to stress. Perlman D, Jones. editors. Greenwich: CT: JAI; 1987. pp. 37-67.

25. Rosenstock IM, Strecher VJ, Becker MH. Social learning theory and the Health Belief Model. Health Educ Q.1988;15(2):175-83.

26. Dworkin SL, Hatcher AM, Colvin C, Peacock D. Impact of a Gender-Transformative HIV and Antiviolence Program on Gender Ideologies and Masculinities in Two Rural, South African Communities. Men Masc. 2013;16(2). 